Vol. 8, Issue 8, August 2021

DOI: $10.17148 / I A R J S E T .2021 .8883$

\title{
ROLE OF MENTAL HEALTH PROFESSIONALS DURING COVID-19
}

\author{
Dr. Gouri Manik Manas
}

Associate Professor, Dept. of Social Work, VSK, University, Ballari- Karnataka

\begin{abstract}
The COVID-19 pandemic has led in the worldwide crisis. The presently, everyone has focusing on the prevention of the COVID-19 infection, preparing and the discussions has made on issues related to physical health consequences. It's very important to understand that the people life-threatening in negative physical health consequences are going to face everyone the negative mental health consequences in the pandemic era. The COVID-19 hospitals are being established in various places, to address the physical health consequences of the pandemic. The mental health professionals are very actively involved to manage the people facing this pandemic. On this view so many discussions had made with the mental health professionals who are working with the COVID-19 hospitals, people who are undergoing quarantine, admitted to the COVID-19 hospitals, and those recovered from the Covid infection. The presents paper an overview of the Role of Mental Health Professionals during COVID-19.
\end{abstract}

Key Words: COVID-19. Mental Health, Mental Health Professional and Role of Mental Health Professionals During COVID-19

\section{INTRODUCTION:}

The newly identified novel coronavirus, COVID-19, was first reported in Wuhan, China, in late 2019. The COVID-19 virus is now known to belong to the same family as SARS and Middle East respiratory syndrome coronavirus (MERS$\mathrm{CoV}$ ), which are zoonotic infections thought to have originated from snakes, bats, and pangolins at the Wuhan wet markets. The virus has rapidly spread across the globe leading to many infected people and multiple deaths especially of the elderly and vulnerable. While efforts to control and limit the spread of the pandemic in the community are quite straight forward to follow, it seems that prejudice and fear have jeopardized the response efforts

Mental health is an integral and essential component of health. According to WHO: "Health is a state of complete physical, mental and social well-being and not merely the absence of disease or infirmity." An important implication of this definition is that mental health is more than just the absence of mental disorders or disabilities.

The mental health professional is a health care practitioner or social and human services provider who offers services for the purpose of improving an individual's mental health or to treat mental disorders. This broad category was developed as a name for community personnel who worked in the new community mental health agencies begun in the 1970s to assist individuals moving from state hospitals, to prevent admissions, and to provide support in homes, jobs, education, and community.

The cause of COVID-19 social disruption through growing disease-related stigma and xenophobia against some cultural, national, racial or religious groups worldwide. COVID-19 arisen the unknown and newly emerged highly contagious infection that spreading to rapidly across the globe and associated with the high mortality, leading to fear of encountering those infected. In the present moment, exponential growth in the number of cases and increasing the mortality rate through worldwide defines the COVID-19 pandemic.

\section{OBJECTIVES:}

1. To know the status of the mental health during COVID-19.

2. To analyse the role of mental health professionals during COVID-19.

\section{METHODOLOGY:}

This research paper is basically descriptive and analytical in nature. In this paper attempt has taken to analyse the mental health, mental health professional and role of mental health professionals during covid-19. The data used in this study is purely from secondary sources according to the need of this study. 


\title{
International Advanced Research Journal in Science, Engineering and Technology
}

\author{
Vol. 8, Issue 8, August 2021
}

DOI: $10.17148 /$ IARJSET.2021.8883

\section{Status of Mental}

Worldwide people are experiences in the enormous mental health challenges and they are also infected with the COVID19 or not. The mental health challenges affect different groups of people (general population, COVID-19 patients, elderly, health care workers, marginalized population) differently in terms of its nature and severity. The COVID-19 has produced the serious crisis in the healthcare worldwide, including the mental health sector. The impact of this intense affected adversely on mental healthcare professionals.

\section{role of mental health professionals during covid-19}

In the present society, people have a common notion that the mental health professionals are having the very strong mental abilities to deal with the challenges. The mental health professionals can't experience stress, fear, anxiety and depression. This belief is level seen among healthcare professionals of non-psychiatric discipline. The fact is mental health professionals are also human beings and are not immune to psychiatric illnesses, frustrations, stress, guilt, fear, anxiety and depression. Mental health professionals are also facing the similar kind of situation in their family and immediate society.

In pandemic period society is going to expects from the mental health professionals has to care the patient, strongly motivate them, available for patient anytime, mental health professionals. free from stress and frustrations at the time of need and simultaneously stigmatizes psychiatry.

In the present pandemic situation, the mental health professionals are ignored to take care of their mental health. They seek adequately to help for themselves and possibly out of some belief that experts they are fail to deal with their mental health problems on own and lack of engaging environment and support to those having the psychiatric illnesses during COVID-19 pandemic makes them more vulnerable. Already high suicide rates, marital disharmony, addiction among the psychiatrists, deterioration of their mental health has to anticipated for timely action and then mental health utmost importance for everybody, including the mental health professionals.

\section{Mental Health professional's role throughout the pandemic includes:}

$>\quad$ Self-care and attention personal and professional wellbeing in challenging situations

$>\quad$ Maintaining professional integrity and professional standards

$>\quad$ Ensuring as much continuity in contact, support and services as possible, including through enhanced use of digital communications

$>\quad$ Using statutory powers well and maintaining highest ethical practice in an emergency, pressurised context

\section{Findings:}

1. Pandemic period has the number of mental health issues related to COVID-19 is emerging exponentially, it puts the mental health professionals under tremendous pressure and they are dealing with the mental health issues.

2. The mental health professionals are engaged in the additional responsibility i.e., COVID-19 training and duty in the isolation wards of COVID hospitals. Accordingly, this is demanding situation for role of mental health professionals is highly crucial.

3. In the lockdown period closure of essential services resulted in limiting the access to mental healthcare in majority of the places. Telepsychiatry emerged the alternative to conventional mental healthcare delivery. Now days increasing the number of phone calls and mails for digital consultation had given new shape to the mental healthcare settings.

4. The mental healthcare demand is high during this current COVID-19 pandemic period and mental health professionals have to shoulder this responsibility, it is likely to increase their stress and adversely affect their own mental health.

5. As a mental health professional, one should take care for their mental health first and should not shy away from seeking other's help 


\section{International Advanced Research Journal in Science, Engineering and Technology}

Vol. 8, Issue 8, August 2021

DOI: $10.17148 /$ IARJSET.2021.8883

\section{CONCLUSION}

Mental status worsens during pandemic. So continuous examination of both physical and mental status of those affected by COVID 19 are needed. Although very few symptom manifestations of depression, anxiety and stress may be normal during pandemic outbreak, still severe level of these symptoms are indicating toward mental illness and urgent need of psychological interventions by mental health professionals.

WHO is providing the guidance and advice during the COVID-19 pandemic for the health workers, managers of health facilities, people who are looking after children, older adults and people who isolated and members of the public generally, to help them to look after their mental health.

\section{REFERENCES:}

1. Bergman J. The suicide rate among psychiatrists revisited. Suicide Life-Threatening Behav. 1979;9:219-226. [PubMed] [Google Scholar] 2. Galbraith N., Boyda D., McFeeters D., Hassan T. The mental health of doctors during the COVID-19 pandemic. BJPsych Bull. $2020: 1-4$. doi: 10.1192/bjb.2020.44. [PMC free article] [PubMed] [CrossRef] [Google Scholar]

3. Gerada C. Doctors, suicide and mental illness. BJPsych Bull. 2018;42:165-168. doi: 10.1192/bjb.2018.11. [PMC free article] [PubMed] [CrossRef] [Google Scholar]

4. Ji, W. , Wang, W. , Zhao, X. , Zai, J. , \& Li, X. (2020). Cross-species transmission of the newly identified coronavirus 2019-nCoV. Journal of Medical Virology, 92(4), 433-440. [PMC free article] [PubMed] [Google Scholar

5. $\quad$ Roy D., Tripathy S., Kar S.K., Sharma N., Verma S.K., Kaushal V. Study of knowledge, attitude, anxiety \& perceived mental healthcare need in Indian population during COVID-19 pandemic. Asian J. Psychiatry. 2020 doi: 10.1016/j.ajp.2020.102083. [PMC free article] [PubMed] [CrossRef] [Google Scholar]

6. Tandon R. COVID-19 and mental health: preserving humanity, maintaining sanity, and promoting health. Asian J. Psychiatry. 2020;51 doi: 10.1016/j.ajp.2020.102256. [PMC free article] [PubMed] [CrossRef] [Google Scholar]

7. Tandon R. The COVID-19 pandemic, personal reflections on editorial responsibility. Asian J. Psychiatry. 2020;50 doi: 10.1016/j.ajp.2020.102100. [PMC free article] [PubMed] [CrossRef] [Google Scholar]

8. Wang, W. Tang, T. \& Wei, F. (2020). Updated understanding of the outbreak of 2019 novel coronavirus (2019-nCoV) in Wuhan, China. Journal of Medical Virology, 92 (4), 441-447. 